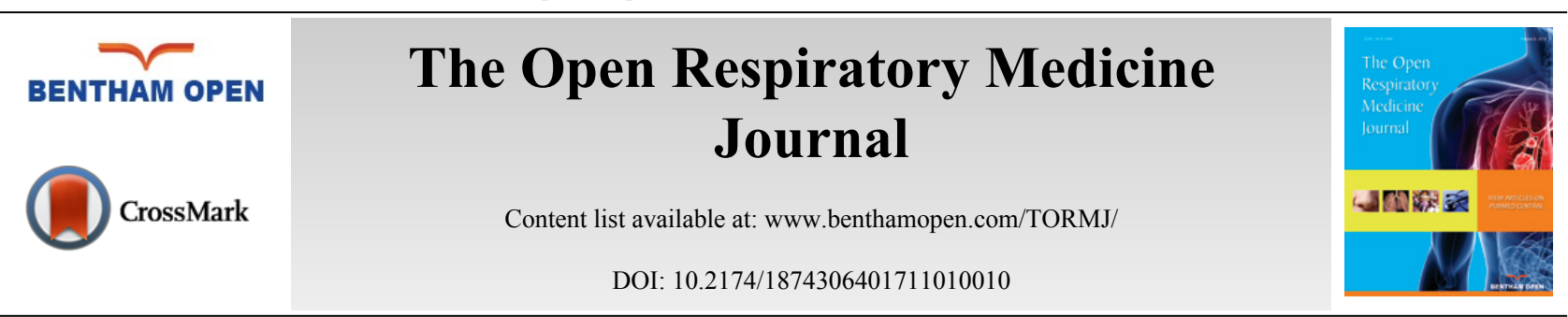

RESEARCH ARTICLE

\title{
24-Hour Hypoxia and Pulmonary Hypertension in Patients with Idiopathic Pulmonary Fibrosis
}

\author{
Marcelo P. Rodrigues ${ }^{1, *}$, Carolina M. Vissoci ${ }^{2}$, Samuel P. Rosa ${ }^{3}$ and Sandra B.C. Negreiros ${ }^{1}$ \\ ${ }^{I}$ Department of Pulmonology, School of Medicine, Universidade de Brasilia (UnB), Brasilia, DF, Brazil \\ ${ }^{2}$ Student of Medicine. School of Medicine, UnB, Brasilia, DF, Brazil \\ ${ }^{3}$ Department of Cardiology, Hospital de Base, Brasilia, DF, Brazil
}

Received: December 09, 2016

Revised: March 03, 2017

Accepted: March 03, 2017

\begin{abstract}
:
Background:

The quantification of hypoxia based on resting partial pressure of arterial oxygen $\left(\mathrm{PaO}_{2}\right)$ may underestimate hypoxia related to activities of daily living or sleep and thus not accurately reflect pulmonary hypertension (PH). The aim of the present study was to investigate the association of resting $\mathrm{PaO}_{2}$ with percent time of $\mathrm{SpO}_{2}$ below 90\% (T90) and 88\% (T88) in 24 hours. We also evaluated the capacity of hypoxia measures to predict $\mathrm{PH}$ in patients with idiopathic pulmonary fibrosis (IPF).
\end{abstract}

\section{Method:}

This cross-sectional study included 27 patients with IPF presenting $\mathrm{PaO}_{2} \geq 55 \mathrm{mmHg}$ and not receiving home oxygen therapy. All were submitted to blood gas measurement, 24-h oximetry, and transthoracic Doppler echocardiography to estimate systolic pulmonary artery pressure (SPAP). Patients were divided into three groups according to resting $\mathrm{PaO}_{2}: 55-55.9 \mathrm{mmHg}$ (A); $60-60.9 \mathrm{mmHg}(\mathrm{B}) ; \geq 70 \mathrm{mmHg}(\mathrm{C})$. PH was defined as "likely" if SPAP $>50 \mathrm{mmHg}$, and as possible for SPAP between 37 and $50 \mathrm{mmHg}$.

\section{Results:}

T90 and T88 in Groups A, B, and C were as follows: $59.9 \pm 29 \%$ and $44.1 \pm 34 \% ; 49.3 \pm 34 \%$ and $29.9 \pm 31 \% ; 17.1 \pm 25 \%$ and $8.8 \pm 18 \%$ respectively, with significant differences between the groups for both $\mathrm{T} 90(p \leq 0.01)$ and $\mathrm{T} 88(p=0.02)$. $\mathrm{PaO}_{2}$ was inversely correlated with T90 $(\mathrm{r}=-0.398 ; p=0.04)$ and $\mathrm{T} 88(\mathrm{r}=-0.351 ; p=0.07)$. Hypoxia variables did not correlate with SPAP, and were not able to predict $\mathrm{PH}$.

\section{Conclusion:}

Percent time of $\mathrm{SpO}_{2}$ below $90 \%$ and $88 \%$ in 24 hours revealed periods of severe hypoxia even in patients with borderline-normal resting $\mathrm{PaO}_{2}$. However, none of the present hypoxia variables was capable of predicting $\mathrm{PH}$.

Keywords: Hypertension, Pulmonary, Hypoxia, Idiopathic pulmonary fibrosis, Blood gas monitoring, Transcutaneous.

\section{INTRODUCTION}

Pulmonary hypertension (PH) is a common finding in patients with idiopathic pulmonary fibrosis (IPF), and increases in frequency and intensity with the progression of IPF [1]. PH is associated with significant reduction in IPF survival, and thus has important prognostic implications for IPF patients $[2,3]$.

\footnotetext{
* Address correspondence to this author at the SQSW 306, B, 603, Setor Sudoeste 70673-432 - Brasília, DF, Brazil, Tel: +55-61-8433-0879; E-mail: pmarcelo27@gmail.com
} 
Traditionally, PH associated with chronic lung diseases has been attributed to alveolar hypoxia. Animal models suggest that chronic alveolar hypoxia causes PH through a combination of sustained vasoconstriction and vascular remodeling. It is generally accepted that vasoconstriction plays a major role during initial stages of the disease, whereas structural remodeling of the pulmonary vascular bed becomes more important during later stages of the disease. This hypothesis is supported by the observation that oxygen administration becomes less effective to reduce pulmonary arterial pressure with increased duration of chronic alveolar hypoxia. The lack of response to oxygen therapy, in turn, suggests that PH results, at least in part, from structural remodeling that is irreversible or only minimally reversible [4]. Nevertheless, there is no consensus on this issue, even in animal models; in rats, Hyvelin et al. [5] have shown that sustained vasoconstriction, largely dependent on Rho-kinase action, plays a more important role in the development of hypoxia-induced PH than structural vascular changes.

An aspect that has been overlooked regarding the role of hypoxia in the establishment of $\mathrm{PH}$ is the method used to measure the degree of hypoxia. Peripheral capillary oxygen saturation $\left(\mathrm{SpO}_{2}\right)$ often decreases during exercise in patients with IPF. In addition, the severity of intermittent sleep oxygen desaturation has been previously associated with shorter survival in patients with IPF [6]. Thus, quantifying hypoxia based strictly on resting partial pressure of arterial oxygen $\left(\mathrm{PaO}_{2}\right)$ may mask the impact of activities of daily life and sleep.

The present study aimed at correlating resting $\mathrm{PaO}_{2}$ with duration of $\mathrm{SpO}_{2}$ below 90\% (T90) and 88\% (T88) in 24 hours (to incorporate the effect of activities of daily living and sleep) in a group of patients with IPF. In addition, we evaluated the ability of different hypoxia measures to predict $\mathrm{PH}$ in this sample.

\section{METHOD}

A cross-sectional study was carried out with 27 patients selected consecutively from the Interstitial Lung Disease Clinic at a tertiary referral hospital (Hospital Universitário de Brasília). IPF was diagnosed according to American Thoracic Society/European Respiratory Society criteria [7]. In 10 patients (37\%), surgical lung biopsy was required to confirm the diagnosis. In the remaining 17 patients, clinical and radiologic criteria were considered to be sufficient for diagnosis. Additional inclusion criteria were stable clinical status, resting $\mathrm{PaO}_{2} \geq 55 \mathrm{mmHg}$, and not receiving home oxygen therapy. Exclusion criteria were chronic pulmonary thromboembolism and clinical or echocardiographic evidence of left ventricular dysfunction.

The study was approved by the Ethics Committee at Universidade de Brasília. All participants signed an informed consent form.

\subsection{Spirometry and Determination of $\mathrm{PaO}_{2}$ and 24-h $\mathrm{SpO}_{2}$}

Forced vital capacity (FVC) was determined following American Thoracic Society guidelines [8]. For blood gas measurements, blood was drawn from the non-dominant arm radial artery. Blood samples were collected after a 20-min rest in the sitting position and local anesthesia with $2 \%$ lidocaine solution. Blood samples were analyzed in a blood gas analyzer for 3 minutes or less (AVL Compact 3, Graz, Austria). The alveolar gas equation was used to calculate $\mathrm{D}_{\mathrm{A} \text {-a02 }}$ considering a local atmospheric pressure of $680 \mathrm{mmHg}$, with respiratory quotient of 0.8 for all patients.

For the present study, patients were divided into 3 groups, according to resting $\mathrm{PaO}_{2}$ : borderline for indication of home oxygen therapy $\left(\mathrm{PaO}_{2} 55\right.$ to $55.9 \mathrm{mmHg}$ (Group A); intermediate $\left(\mathrm{PaO}_{2}\right.$ between 60 and $69.9 \mathrm{mmHg}$ ) (Group B); and mild hypoxia or normal $\mathrm{PaO}_{2}\left(\mathrm{PaO}_{2}=70 \mathrm{mmHg}\right.$ ) (Group C).

Oxygen saturation was measured over 24 hours using a wrist-worn pulse oximeter (Nonin 3100, Minneapolis, USA) attached to the index finger in the non-dominant hand. Patients were instructed to keep their habitual activities. 24-h measurements were analyzed using the $\mathrm{nVision}$ software v. 5.1e (Nonin, Minneapolis, USA). The percentage of wake and sleep time with $\mathrm{SpO}_{2}$ below $90 \%$ (T90) and $88 \%$ (T88) was measured in relation to the total 24-h period.

\subsection{Measurement of SPAP and PH}

Transthoracic Doppler echocardiography was performed with patients in the lateral recumbent position using an ultrasound device (General Electric, VIVID S5, Milwaukee, USA) with multi-frequency transducer (2.5 to $3.5 \mathrm{MHz}$ ). Standard projections were used.

Chamber quantification and ventricular function assessment were performed as recommended by the American Society of Echocardiography [9]. Real-time Doppler color flow mapping was used to more accurately assess tricuspid 
regurgitation. Continuous wave Doppler with sweep speed of 50-100 mm/s was used. Three to five measurements were performed per parameter.

SPAP was calculated based on tricuspid regurgitation using the modified Bernoulli equation. The pressure gradient between the right ventricle and right atrium was thus obtained. Estimated right atrial pressure was added to the Dopplerdetermined gradient [10], considering an unobstructed right ventricular outflow tract. Right atrial pressure estimates were based on inferior vena cava percentage collapse during spontaneous breathing. If inspiratory collapse was greater than $50 \%$ and initial diameter was smaller than $2.1 \mathrm{~cm}$, an estimated right atrial pressure of $5 \mathrm{mmHg}$ was added to the Doppler-determined gradient; if the collapse was $50 \%$ or more and the initial diameter $\geq 2.1 \mathrm{~cm}, 10 \mathrm{mmHg}$ were added. In patients with inferior vena cava dilatation to a diameter significantly higher than $2.1 \mathrm{~cm}$ and collapse significantly less than 50\%, $20 \mathrm{mmHg}$ were added [11 - 13].

PH was defined as "likely" if SPAP $>50 \mathrm{mmHg}[13,14]$. PH was defined as possible for SPAP between 37 and $50 \mathrm{mmHg}$, or for SPAP below this level in the presence of the following echocardiographic findings: right ventricular dilatation and/or hypertrophy, paradoxical septal motion, or right ventricular dysfunction according to American Society of Echocardiography recommendations for assessment of right ventricle [13].

\subsection{Statistical Analysis}

The distribution of continuous variables was determined using the Kolmogorov-Smirnov test as well as a Q-Q plot, a graphical representation in which normal distribution is represented by a straight diagonal line. Since all variables under study (T90, T88, $\mathrm{PaO}_{2}, \mathrm{D}_{\mathrm{A}-\mathrm{aO} 2}$, SPAP) had normal distribution, group means were compared using one-way analysis of variance (ANOVA). Correlations were evaluated using Pearson's coefficient. For the binary yes/no variables (likely $\mathrm{PH}$ and combined analysis of possible + likely $\mathrm{PH}$ ) logistic models were employed for each indicator of hypoxia (T90, T88, $\mathrm{PaO}_{2}, \mathrm{D}_{\mathrm{A}-\mathrm{aO} 2}$ ), and odds ratios were calculated for these predictors with $95 \%$ confidence intervals. Means are presented with standard deviations. Significance was defined as $p<0.05$. SPSS v. 20 for Mac was used for the analyses.

\section{RESULTS}

The sample of 27 patients included 15 males (55.6\%) and 12 females (44.4\%) and comprised different stages of the disease. Mean age was $71.4 \pm 11$ years, ranging from 43 to 88 years. Mean FVC was $2.23 \pm 0.74 \mathrm{~L}$, ranging from $1.08 \mathrm{~L}$ to 3.63 L. Mean \% of predicted FVC was $72.6 \pm 22 \%$, from $45 \%$ to $93 \%$.

The logistic regression models employed in this study were not capable of predicting $\mathrm{PH}$, either likely or combined analysis of possible + likely PH. Table 1 shows the odds ratios (OR) for each predictor variable analyzed (T90, T88, $\mathrm{PaO}_{2}$, and $\mathrm{DA}-\mathrm{aO}_{2}$ ).

Table 1. Ability of hypoxia variables to predict pulmonary hypertension.

\begin{tabular}{|c|c|c|c|c|}
\hline & \multicolumn{4}{|c|}{ Pulmonary hypertension } \\
\hline & \multicolumn{2}{|c|}{$\begin{array}{l}\text { Combined analysis of possible+ likely } \\
\qquad(n=12)\end{array}$} & \multicolumn{2}{|l|}{$\begin{array}{l}\text { Likely } \\
(n=5)\end{array}$} \\
\hline & OR & $p$ & OR & $p$ \\
\hline T90 (\%) & $1.005(0.982-1.029)$ & 0.66 & $1.014(0.986-1.043)$ & 0.31 \\
\hline T88 (\%) & $1.004(0.978-1.031)$ & 0.77 & $1.008(0.97-1.040)$ & 0.61 \\
\hline $\mathrm{PaO}_{2}(\mathrm{mmHg})$ & $0.979(0.910-1.054)$ & 0.57 & $0.945(0.853-1.048)$ & 0.28 \\
\hline $\mathrm{DA}-\mathrm{aO}{ }_{2}(\mathrm{mmHg})$ & $1.008(0.931-1.091)$ & 0.84 & $1.001(0.905-1.107)$ & 0.99 \\
\hline
\end{tabular}

Along the same lines, only a weak and non-significant correlation was observed for T90, T88, $\mathrm{PaO}_{2}$, and $_{\mathrm{DA}-\mathrm{aO}}$ with SPAP. SPAP could not be estimated in one patient in whom tricuspid regurgitation was absent, and thus 26 patients were included in this analysis. Pearson's coefficients for the correlation between SPAP and hypoxia variables were as follows: $-0.197(p=0.33)$ for $\mathrm{PaO}_{2} ; 0.099(p=0.62)$ for $\mathrm{DA}-\mathrm{aO}_{2} ; 0.191(p=0.35)$ for T90; and $0.157(p=0.44)$ for T88.

Despite the inability of hypoxia data to predict PH and the lack of correlation with SPAP values, the results show that 24-h hypoxia levels were higher than expected considering resting $\mathrm{PaO}_{2}$ measurements. Table 2 shows T90 and T88 values according to hypoxia severity. Fig. (1A and B) emphasize these individual values in a scatterplot. It should be noted that even in patients with borderline normal $\mathrm{PaO}_{2}, \mathrm{SpO}_{2}$ below $90 \%$ was detected during a period corresponding to $17 \%$ of the day, that is, more than $4 \mathrm{~h}$. This hypoxia duration was higher in groups with lower $\mathrm{PaO}_{2}$, 
with statistically significant differences. Indeed, resting $\mathrm{PaO}_{2}$ had a negative and moderate correlation with T90 ( $\mathrm{r}=-0.398 ; p=0.04)$, but not with T88 ( $\mathrm{r}=-0.351 ; 0.07)$. None of the patients presented T90 or T88 of zero, although six patients of the 15 classified in group $\mathrm{C}\left(\mathrm{PaO}_{2}=70 \mathrm{mmHg}\right)$ had $\mathrm{T} 90<2 \%$.

Table 2. Comparison of percent hypoxia time and systolic pulmonary artery pressure in patients with different degrees of resting $\mathrm{PaO}_{2}$.

\begin{tabular}{|l|c|c|c|c|}
\hline & \multicolumn{3}{|c|}{ PaO $_{2}$} & \\
\hline & $\begin{array}{c}\mathbf{5 5 - 5 5 . 9} \mathbf{~ m m H g} \\
(\boldsymbol{n}=\mathbf{6})\end{array}$ & $\begin{array}{c}\mathbf{6 0 - 6 9 . 9} \mathbf{~ m m H g} \\
(\boldsymbol{n}=\mathbf{6})\end{array}$ & $\begin{array}{c}\geq \mathbf{7 0} \mathbf{~ m m H g} \\
(\boldsymbol{n}=\mathbf{1 5})\end{array}$ & $\boldsymbol{p}$ \\
\hline $\mathrm{T}^{\mathrm{a}} \mathrm{a}$ & $59.9 \pm 29$ & $49.3 \pm 34$ & $17.1 \pm 25$ & $<0.01$ \\
\hline $\mathrm{T} 88^{\mathrm{b}}$ & $44.1 \pm 34$ & $29.9 \pm 31$ & $8.8 \pm 18$ & 0.02 \\
\hline $\mathrm{SPAP}(\mathrm{mmHg})$ & $47 \pm 31$ & $36 \pm 20$ & $35 \pm 10$ & 0.38 \\
\hline
\end{tabular}

$\%$ time with $\mathrm{SpO}_{2}<90 \%$ in $24 \mathrm{~h}$.

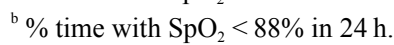

The analysis of sleep and wake periods revealed higher T90 and T88 during sleep, however without statistical significance. In six patients, we were unable to adequately discriminate between sleep and wake periods, and thus 21 patients were included in this analysis. Mean T90 was $30.7 \%$ and $37.1 \%$ during wake and sleep periods respectively $(p=0.08)$. Mean T88 was $18.2 \%$ and $22.6 \%$ during wake and sleep periods respectively $(p=0.18)$. Hemoglobin saturation declined at a slightly higher hourly rate during the wake period, 11.6 vs. 10.9 during sleep $(p=0.63)$.
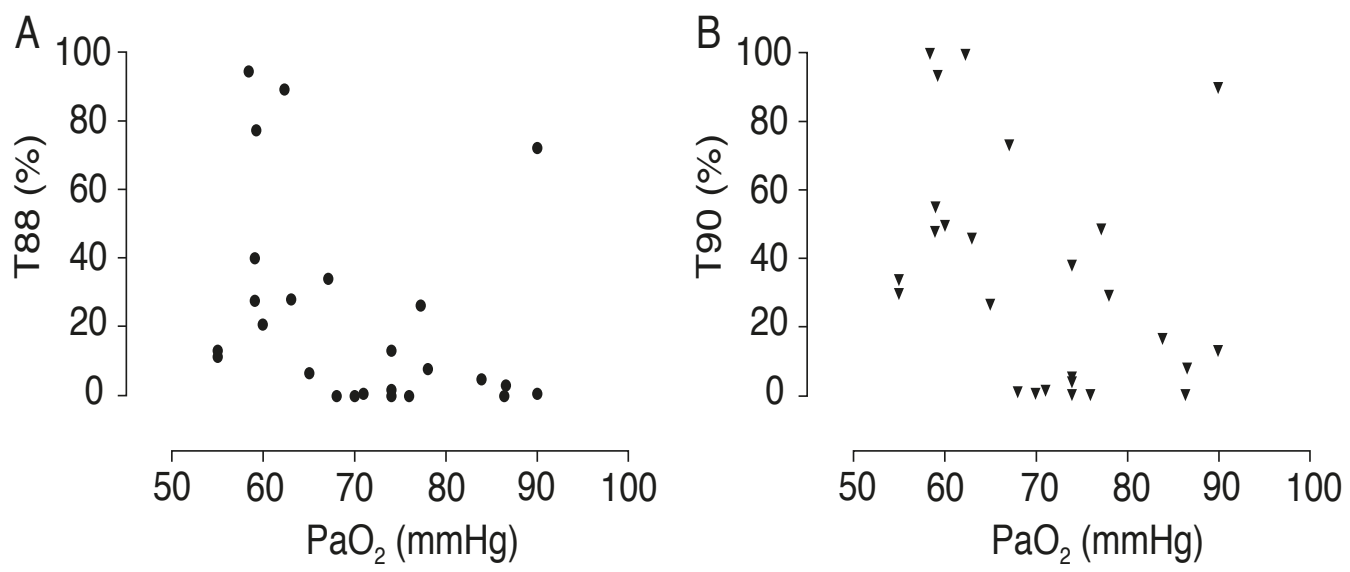

Fig. (1). Percent time with $\mathrm{SpO}_{2}$ below $88 \%$ (T88) in 24 hours according to $\mathrm{PaO}_{2}$.

\section{DISCUSSION}

The present results did not reveal a correlation between degree of hypoxia and PH. In fact, none of the hypoxia variables analyzed was capable of predicting $\mathrm{PH}$, and there was no relevant correlation between hypoxia variables and SPAP. These data support the notion that other pathogenic mechanisms are probably involved the development of PH in IPF patients.

Hypoxia may induce $\mathrm{PH}$ through vasoconstriction or structural vascular changes, i.e. remodeling. Several alterations have been described in this situation, affecting arteries, arterioles and venules and destroying the capillary bed. Thickening of the adventitia has been described as a result of increased deposition of extracellular matrix proteins with accumulation of fibroblasts and myofibroblasts. Intima-media thickening may also be caused by smooth muscle hypertrophy and hyperplasia, in addition to collagen and elastin deposition. Muscularization of distal lung arterioles, a known feature of hypoxia-induced remodeling, has also been described. In addition, intimal hyperplasia has been described in IPF patients, together with fibrosis and duplication of the elastic lamina typical of small muscular pulmonary arteries [15].

Nevertheless, until the present moment, there is no significant evidence of morphological differences between the structural vascular changes affecting patients with PH induced by hypoxia or other reasons. Therefore it is not possible 
to affirm that other mechanisms besides hypoxia are implicated in PH in patients with IPF based solely on histopathological features.

Beyond these structural changes, a remarkable functional finding reported in the literature is the lack of correlation between lung volumes and $\mathrm{PH}$ [16]. One possible explanation for that would be the lack of a direct link between PH development and the extent of interstitial remodeling in IPF. Considering additional mechanisms of PH other than hypoxia, the dissociation between fibrosis and PH could be explained, at least in part, by endothelial dysfunction [16].

When looking at the biochemical changes related to hypoxia, it is possible to affirm that hypoxia and inflammation are inseparably intertwined [17]. If on the one hand hypoxia triggers the appearance of mediators that will ultimately lead to $\mathrm{PH}$, on the other hand it is possible to speculate that such mediators constitute a physiological pathway that is shared with other triggering factors stemming from the inflammatory and/or fibrogenic process.

In this sense, several mediators have been implicated in both IPF and idiopathic pulmonary arterial hypertension [18]. For example, an increase in the production of profibrogenic leukotrienes has been reported in both conditions [19, 20]. This in turn causes an elevation in tumor necrosis factor alpha and in platelet- and fibroblast-derived growth factors, which are involved in vascular remodeling and lung fibrosis. A reduction in prostaglandin E2 levels has also been described, which may lead to further collagen deposition in the pulmonary interstitium and to further vascular remodeling [19].

Still regarding mediators, there is evidence of elevated serum levels of endothelin-1 in patients with IPF [21], as well as in patients with idiopathic pulmonary arterial hypertension [22]. Endothelin-1 is a potent vasoconstrictor that induces smooth muscle cell activity.

Nevertheless, the evidence regarding these shared mediators is not sufficient to produce a consistent explanatory model for the pathogenesis of PH. Also, it is not possible to assume that patients with IPF will inevitably develop PH. A large number of these patients do not have PH; and whereas treatment with bosentan, an endothelin-1 antagonist, was effective to treat idiopathic pulmonary arterial hypertension, it did not produce improvement in patients with IPF and $\mathrm{PH}[23]$.

In the present study, the cross-sectional design prevented us from analyzing the long-term impact of hypoxia duration in each patient. Nevertheless, our data show hypoxia occurring in connection with activities of daily living even in patients with resting $\mathrm{PaO}_{2}>70 \mathrm{mmHg}$. This suggests the presence of hypoxia early on in IPF.

Based on our data, it is possible to speculate that the duration of disease in the presence of hypoxia may be more important than the intensity of hypoxia to predict PH. However, hypoxia is likely not the only mechanism triggering PH. There are no epidemiological data linking PH to slower development of IPF, a situation which would imply longer time of exposure to hypoxia.

Indirect evidence contrary to hypoxia as a pathogenic factor in PH and IPF have been obtained by Pouwels-Fry et al. [24], who observed that oxygen therapy does not interfere with the increase in SPAP during exercise in patients with IPF. In a different scenario, Blanco et al. [25] studied the effect of nitric oxide administration during rest and exercise in patients with IPF and observed a reduction in mean pulmonary artery pressure in both states, without significant changes in $\mathrm{PaO}_{2}$ or in ventilation/perfusion distributions. Differently from Pouwels-Fry et al., these authors found a strong and significant correlation between mean pulmonary artery pressure and 6-keto-prostaglandin- $\mathrm{F}_{1 \alpha}$, an endothelium-derived molecule.

Regarding sleep and wake periods, hypoxia duration (T88 and T90) was slightly higher during sleep, even though the comparison was not statistically significant. This was probably due to the hypoventilation that occurs during sleep even in normal individuals [26]. No significant differences were observed between hourly hemoglobin desaturation index during sleep vs. wake period. Even though this finding is difficult to interpret (since during wake periods the effort associated with activities of daily living is a clear additional influence), it does not support the notion of severe respiratory sleep disturbances in this sample of patients.

\section{CONCLUSION}

T90 and T88 measures in 24 hours reflect hypoxia in patients with borderline-normal $\mathrm{PaO}_{2}$. However, based on the present results, these variables are not useful to predict $\mathrm{PH}$ in IPF. The same was true for $\mathrm{PaO}_{2}$ and $\mathrm{DA}-\mathrm{aO}_{2}$. 


\section{ETHICS APPROVAL AND CONSENT TO PARTICIPATE}

Not applicable.

\section{HUMAN AND ANIMAL RIGHTS}

No Animals/Humans were used for studies that are base of this research.

\section{CONSENT FOR PUBLICATION}

Not applicable.

\section{FINANCIAL DISCLOSURE}

The authors have no financial relationships relevant to this article to disclose.

\section{CONFLICT OF INTEREST}

The author confirms that this article content has no conflict of interest.

\section{ACKNOWLEDGEMENTS}

Decleared none.

\section{REFERENCES}

[1] Nathan SD, Shlobin OA, Ahmad S, et al. Serial development of pulmonary hypertension in patients with idiopathic pulmonary fibrosis. Respiration 2008; 76(3): 288-94

[http://dx.doi.org/10.1159/000114246] [PMID: 18216461]

[2] Nadrous HF, Pellikka PA, Krowka MJ, et al. Pulmonary hypertension in patients with idiopathic pulmonary fibrosis. Chest 2005; 128(4): 2393-9.

[http://dx.doi.org/10.1378/chest.128.4.2393] [PMID: 16236900]

[3] Rivera-Lebron BN, Forfia PR, Kreider M, Lee JC, Holmes JH, Kawut SM. Echocardiographic and hemodynamic predictors of mortality in idiopathic pulmonary fibrosis. Chest 2013; 144(2): 564-70. [http://dx.doi.org/10.1378/chest.12-2298] [PMID: 23450321]

[4] Stenmark KR, McMurtry IF. Vascular remodeling versus vasoconstriction in chronic hypoxic pulmonary hypertension: a time for reappraisal? Circ Res 2005; 97(2): 95-8.

[http://dx.doi.org/10.1161/01.RES.00000175934.68087.29] [PMID: 16037575]

[5] Hyvelin JM, Howell K, Nichol A, Costello CM, Preston RJ, McLoughlin P. Inhibition of Rho-kinase attenuates hypoxia-induced angiogenesis in the pulmonary circulation. Circ Res 2005; 97(2): 185-91. [http://dx.doi.org/10.1161/01.RES.0000174287.17953.83] [PMID: 15961717]

[6] Kolilekas L, Manali E, Vlami KA, et al. Sleep oxygen desaturation predicts survival in idiopathic pulmonary fibrosis. J Clin Sleep Med 2013; 9(6): 593-601. [PMID: 23772193]

[7] Raghu G, Collard HR, Egan JJ, et al. An official ATS/ERS/JRS/ALAT statement: idiopathic pulmonary fibrosis: evidence-based guidelines for diagnosis and management. Am J Respir Crit Care Med 2011; 183(6): 788-824. [http://dx.doi.org/10.1164/rccm.2009-040GL] [PMID: 21471066]

[8] American Thoracic Society. 1994 Update. Am J Respir Crit Care Med 1995; 152(3): 1107-36. [PMID: 7663792]

[9] Lang RM, Bierig M, Devereux RB, et al. Recommendations for chamber quantification: a report from the American Society of Echocardiographys Guidelines and Standards Committee and the Chamber Quantification Writing Group, developed in conjunction with the European Association of Echocardiography, a branch of the European Society of Cardiology. J Am Soc Echocardiogr 2005; 18(12): 1440-63. [http://dx.doi.org/10.1016/j.echo.2005.10.005] [PMID: 16376782]

[10] Berger M, Haimowitz A, Van Tosh A, Berdoff RL, Goldberg E. Quantitative assessment of pulmonary hypertension in patients with tricuspid regurgitation using continuous wave Doppler ultrasound. J Am Coll Cardiol 1985; 6(2): 359-65. [http://dx.doi.org/10.1016/S0735-1097(85)80172-8] [PMID: 4019921]

[11] Ommen SR, Nishimura RA, Hurrell DG, Klarich KW. Assessment of right atrial pressure with 2-dimensional and Doppler echocardiography: a simultaneous catheterization and echocardiographic study. Mayo Clin Proc 2000; 75(1): 24-9. [http://dx.doi.org/10.4065/75.1.24] [PMID: 10630753]

[12] Currie PJ, Seward JB, Chan KL, et al. Continuous wave Doppler determination of right ventricular pressure: a simultaneous Dopplercatheterization study in 127 patients. J Am Coll Cardiol 1985; 6(4): 750-6. [http://dx.doi.org/10.1016/S0735-1097(85)80477-0] [PMID: 4031289] 
[13] Rudski LG, Lai WW, Afilalo J, et al. Guidelines for the echocardiographic assessment of the right heart in adults: a report from the American Society of Echocardiography endorsed by the European Association of Echocardiography, a registered branch of the European Society of Cardiology, and the Canadian Society of Echocardiography. J Am Soc Echocardiogr 2010; 23(4): 685-713. quiz 786-688.

[14] Simonneau G, Galiè N, Rubin LJ, et al. Clinical classification of pulmonary hypertension. J Am Coll Cardiol 2004; 43(12)(Suppl. S): 5S-12S. [http://dx.doi.org/10.1016/j.jacc.2004.02.037] [PMID: 15194173]

[15] Stenmark KR, Fagan KA, Frid MG. Hypoxia-induced pulmonary vascular remodeling: cellular and molecular mechanisms. Circ Res 2006; 99(7): 675-91. [http://dx.doi.org/10.1161/01.RES.0000243584.45145.3f] [PMID: 17008597]

[16] Nathan SD, Shlobin OA, Ahmad S, Urbanek S, Barnett SD. Pulmonary hypertension and pulmonary function testing in idiopathic pulmonary fibrosis. Chest 2007; 131(3): 657-63 [http://dx.doi.org/10.1378/chest.06-2485] [PMID: 17356077]

[17] Voelkel NF, Mizuno S, Bogaard HJ. The role of hypoxia in pulmonary vascular diseases: a perspective. Am J Physiol Lung Cell Mol Physiol 2013; 304(7): L457-65. [http://dx.doi.org/10.1152/ajplung.00335.2012] [PMID: 23377344]

[18] Nathan SD, Noble PW, Tuder RM. Idiopathic pulmonary fibrosis and pulmonary hypertension: connecting the dots. Am J Respir Crit Care Med 2007; 175(9): 875-80. [http://dx.doi.org/10.1164/rccm.200608-1153CC] [PMID: 17255562]

[19] Charbeneau RP, Peters-Golden M. Eicosanoids: mediators and therapeutic targets in fibrotic lung disease. Clin Sci 2005; 108(6): 479-91. [http://dx.doi.org/10.1042/CS20050012] [PMID: 15896193]

[20] Wright L, Tuder RM, Wang J, Cool CD, Lepley RA, Voelkel NF. 5-Lipoxygenase and 5-lipoxygenase activating protein (FLAP) immunoreactivity in lungs from patients with primary pulmonary hypertension. Am J Respir Crit Care Med 1998; 157(1): $219-29$. [http://dx.doi.org/10.1164/ajrccm.157.1.9704003] [PMID: 9445303]

[21] Uguccioni M, Pulsatelli L, Grigolo B, et al. Endothelin-1 in idiopathic pulmonary fibrosis. J Clin Pathol 1995; 48(4): 330-4. [http://dx.doi.org/10.1136/jcp.48.4.330] [PMID: 7615852]

[22] Giaid A, Michel RP, Stewart DJ, Sheppard M, Corrin B, Hamid Q. Expression of endothelin-1 in lungs of patients with cryptogenic fibrosing alveolitis. Lancet 1993; 341(8860): 1550-4. [http://dx.doi.org/10.1016/0140-6736(93)90694-C] [PMID: 8099638]

[23] Corte TJ, Keir GJ, Dimopoulos K, et al. Bosentan in pulmonary hypertension associated with fibrotic idiopathic interstitial pneumonia. Am J Respir Crit Care Med 2014; 190(2): 208-17. [http://dx.doi.org/10.1164/rccm.201403-0446OC] [PMID: 24937643]

[24] Pouwels-Fry S, Pouwels S, Fournier C, et al. Effects of oxygen on exercise-induced increase of pulmonary arterial pressure in idiopathic pulmonary fibrosis. Sarcoidosis Vasc Diffuse Lung Dis 2008; 25(2): 133-9. [PMID: 19382532]

[25] Blanco I, Ribas J, Xaubet A, et al. Effects of inhaled nitric oxide at rest and during exercise in idiopathic pulmonary fibrosis. J Appl Physiol 2011; 110: 638-45.

[26] Sowho M, Amatoury J, Kirkness JP, Patil SP. Sleep and respiratory physiology in adults. Clin Chest Med 2014; 35(3): 469-81. [http://dx.doi.org/10.1016/j.ccm.2014.06.002] [PMID: 25156763]

(C) 2017 Rodrigues et al.

This is an open access article distributed under the terms of the Creative Commons Attribution 4.0 International Public License (CC-BY 4.0), a copy of which is available at: https://creativecommons.org/licenses/by/4.0/legalcode. This license permits unrestricted use, distribution, and reproduction in any medium, provided the original author and source are credited. 